\title{
SYPHILIS
}

\section{Syphilis screening and intervention in 500000 pregnant women in Shenzhen, the People's Republic of China}

\author{
J Q Cheng, H Zhou, F C Hong, D Zhang, Y J Zhang, P Pan, Y M Cai
}

This paper is freely available online under the BMJ Journals unlocked scheme, see http://sti.bmi.com/info/unlocked.dtl

See linked editorial p 345

Sex Transm Infect 2007;83:347-350. doi: 10.1136/sti.2006.023655

See end of article for authors' affiliations

Correspondence to: Dr Jinquan Cheng, Shenzhen Center for Disease Control and Prevention, Shenzhen 518020, China; cjinquan@sohu.com

Accepted 29 May 2007

\begin{abstract}
Objectives: To understand the disease epidemiology of syphilis in pregnant women, and to evaluate the effectiveness of the screening and intervention programme, for the purpose of controlling mother-to-child syphilis transmission in Shenzhen, in the People's Republic of China (PRC).

Methods: At the Shenzhen Center for Disease Control and Prevention (SZCDC), we used the toluidine red unheated serum test (TRUST) for the primary screening of pregnant women, and confirmed positive results with the Treponema pallidum particle agglutination (TPPA) test. We informed and treated those with positive results. For the women who chose to proceed with the pregnancy, we clinically screened their babies for congenital syphilis using the 19S-IgM FTA-Abs test.

Results: Between 1 July 2002 and 31 December 2005, we screened 477656 pregnant women for syphilis, of whom 2208 (0.5\%) tested positive. From 2003 to 2005, we collected epidemiological and treatment data from 2019 positive syphilis cases. Of these, 1855 (91.9\%) of the pregnant women received treatment. Among the 1020 infants born to these women, $92(9.0 \%)$ were confirmed to have congenital syphilis. If we exclude the mothers who had syphilis positive babies without undergoing prenatal screening, the project's success rate for mother-to-child transmission intervention was $99.1 \%$.

Conclusions: After four years of implementation, we proved the programme to be successful in preventing mother-to-child syphilis transmission. Further work should be done to ensure the earlier screening and treatment of pregnant women.
\end{abstract}

S yphilis has become a serious problem in China, particularly in pregnant women. If syphilis remains untreated in pregnancy, then miscarriages, fetal and neonatal deaths, and congenital syphilis may result. ${ }^{2}$ Shenzhen had almost eradicated syphilis back in the 1960s. However, syphilis cases started to re-emerge in 1983. There were fewer than 25 annual cases before 1994. From 1995 to 1999, the incidence rate increased by an average of 1.68 times each year, resulting in a five-year growth from 4.4 cases per 100000 people in 1994, to 66.2 cases per 100000 people in $1999 .^{3}$ The serological positive rate in pregnant women ranged from $0.4 \%$ to $0.5 \%$, based on sera surveillance. ${ }^{4}$ In 1996, the first congenital syphilis case was reported in the city, and in 2001 the number had increased to 36 cases. To tackle this problem, and especially to prevent mother-to-child transmission, the Shenzhen local government initiated the syphilis prevention programme for pregnant women in 2001. ${ }^{5}$ Supported by a government special fund, this programme aimed at providing free syphilis screening for all pregnant women living in Shenzhen, and if they tested positive, free follow-ups and treatment too. As recommended by the World Health Organization (WHO) in 1994, the screening instruments and treatment medicines for syphilis were simple, inexpensive, and effective. ${ }^{6} 7$

\section{METHODS \\ Population coverage}

A programme offering free routine syphilis screening to all pregnant women was initiated for the first time in Shenzhen. The programme covered 61 hospitals in all six districts of Shenzhen by July 2002. From 1 July 2002 to 31 December 2005, 477656 pregnant women $(94.0 \%)$ were screened, out of the 507992 who were eligible (that is, they had lived in Shenzhen for 3 months or more, and were pregnant).

\section{Screening}

For pregnant women seeking prenatal care at registered medical institutions or clinics, free screenings were given based on informed consent. The sera we obtained from pregnant women were tested with the toluidine red unheated serum test (TRUST) (Rongsheng Bio-technology Limited Corporation, Shanghai, China). ${ }^{8}$ We retested all positive results with the Treponema pallidum particle agglutination (TPPA) test (Fujirebio Inc, Japan) at SZCDC. Two technicians reviewed each result independently. Any positive results of TRUST that were not confirmed by TPPA were otherwise tested with the fluorescent treponemal antibody absorption (FTA-Abs) test (Euroimmun AG, Germany).

\section{Evaluation, intervention, and follow-up}

After the SZCDC released its results to hospitals, the pregnant women who tested positive for syphilis were advised to accept follow-up visits and treatment. Firstly, we gave our patients standardised questionnaires for enrolment. We then carried out their diagnosis and management according to the PRC's Diagnostic Criteria and Management of Syphilis guidelines, ${ }^{9}$ and the Guidelines for the Prevention and Control of Congenital Syphilis by the US Centers for Disease Control (CDC). ${ }^{10}$ The patients themselves decided whether or not to continue their pregnancies after they were given their risk evaluation results.

If the patients chose to terminate their pregnancies, they were treated as normal syphilis cases and were followed up for

Abbreviations: CDC, Centers for Disease Control; FTA-Abs test, fluorescent treponemal antibody absorption test; PRC, People's Republic of China; SEZ, Shenzhen Economic Zone; STDs, sexually transmitted diseases; SZCDC, Shenzhen Center for Disease Control and Prevention; TPPA, Treponema pallidum particle agglutination; TRUST, toluidine red unheated serum test 
Table 1 Pregnant women screened for syphilis

\begin{tabular}{llcc}
\hline & \multicolumn{2}{l}{ Women screened } & \multicolumn{2}{l}{ Syphilis positive } \\
\cline { 2 - 3 } Year & No eligible* & Actual No (\%) & No (\%) \\
\hline 2002 & 65496 & $58785(89.8)$ & $189(0.3)$ \\
2003 & 127929 & $118235(92.4)$ & $555(0.5)$ \\
2004 & 149400 & $141619(94.8)$ & $637(0.5)$ \\
2005 & 165167 & $159017(96.3)$ & $827(0.5)$ \\
Total & 507992 & $477656(94.0)$ & $2208(0.5)$ \\
\hline *Eligible women were those who had lived in Shenzhen for 3 months or more, and who were pregnant.
\end{tabular}

24 months. Penicillin was the primary choice of treatment. Doctors used either 2.4 million units (MU) of benzathine benzylpenicillin (penicillin G), intramuscularly, weekly for three injections or procaine benzylpenicillin (penicillin G) 0.8 MU every day intramuscularly for 14 consecutive days. For those allergic to penicillin, azithromycin $0.5 \mathrm{~g}$ by mouth twice daily was prescribed for 14 days. Patient follow-ups included clinical check-ups and serological tests once every 3 months in the first year, and once every 6 months in the second year.

For the women who chose to continue their pregnancies, doctors gave benzathine benzylpenicillin, intramuscularly, 2.4 MU weekly for three injections or procaine benzylpenicillin, 0.8 MU every day, intramuscularly for 14 consecutive days. Treatments were administered at the time of diagnosis, and during the 30th to $32 \mathrm{nd}$ week of pregnancy. For those allergic to penicillin, erythromycin $0.5 \mathrm{~g}$ by mouth, four times daily was given for 14 days, or we suggested that the patients consider the termination of the pregnancy. After delivery, follow-up continued for 24 months. Infants born to women who were treated for syphilis were screened for congenital syphilis at birth.

\section{Statistical analysis}

We conducted all of our statistical tests using SPSS, version 12.0. Most of the results in the study were calculated by a $\chi^{2}$ test or by Fisher's exact test. The Mann-Whitney test was used to compare the gestation weeks at the screening of both syphilis positive and syphilis negative pregnant women.

\section{RESULTS}

Of the 477656 pregnant women screened, 2208 (0.5\%) positive cases were detected (table 1). Screening coverage increased from $89.8 \%$ in 2002 to $96.3 \%$ in 2005 .

Although screening and treatment commenced in July 2002, the project did not include any follow-up information until 1 January 2003, when systematic follow-ups and treatment were formally implemented. The following results were based on data from 2003 to 2005, during which period 418871 pregnant women were screened, and 2019 cases proved syphilis positive (table 2).

\section{Demographic and socioeconomic characteristics}

The average age of the cases was 27.2, with actual ages ranging from 18 to 42 (SD 0.2) (table 2). Positive syphilis rates among the different age groups were not statistically significant $(p=0.022)$. In all, $145(7.2 \%)$ were single, $1826(90.4 \%)$ were married, $16(0.8 \%)$ were widowed, and $32(1.6 \%)$ were divorced.

Positive rates were significantly associated with education $(\mathrm{p}=0.000)$, being highest in those women educated up to a junior high level, and lowest in those with higher education. The rates were also significantly associated with occupation $(\mathrm{p}=0.000)$; they were highest in the "commercial or service personnel" and "unemployed" groups, and lowest in the "professional" group.

\section{Treatment}

From 2003 to 2005, 2019 pregnant women were diagnosed with syphilis. Among them, 1855 (91.9\%) opted for treatment, 63 (3.1\%) delayed treatment, $54(2.7 \%)$ declined treatmenteither because the patients were denied their test results, or they were concerned about the side effects of the treatmentand the data regarding treatment for the remaining 47 cases $(2.3 \%)$ were lost.

\section{Outcomes of pregnancy (table 3)}

Out of the 2019 syphilis positive pregnant women, 296 (14.7\%) showed adverse pregnancy outcomes, which included miscarriage, stillbirth, and ectopic pregnancy. Of those who did not, $274(13.6 \%)$ women chose to terminate their pregnancies after risk evaluation, either by induced labour or spontaneous abortion. The other $1402(69.4 \%)$ women chose to continue their pregnancies regardless. A greater percentage of women selected this option in $2004(69.9 \%)$ and 2005 (75.8\%) than in $2003(59.5 \%)$. Over the three years, there was no information on $47(2.3 \%)$ women, who had temporary addresses or were difficult to contact. The case loss rate was higher in 2003 than in 2004 and 2005.

Focusing on the 1402 women who chose to continue pregnancy, $1112(79.3 \%)$ had normal childbirth and 86 (6.1\%) had adverse pregnancy outcomes (which include abortion, dead fetuses, or stillbirth). We had no information on the outcomes of $204(14.6 \%)$ cases, as 114 women had returned to their home towns, and 90 were lost because of address changes. In total, the project confirmed 92 cases of congenital syphilis out of 1112 infants born to syphilis positive mothers over three years.

\section{Factors associated with congenital syphilis (table 4)}

Results showed that the mothers who had never had prenatal examinations, but only went to the hospital for childbirth, accounted for the highest percentage $(63.0 \%)$ of babies with congenital syphilis. The second highest contributors (19.6\%) were the cases of childbirth outside hospitals. Under these circumstances, the mother would notice the infant's abnormality, and take the neonate to the hospital for a check-up. There were seven infants with congenital syphilis born to syphilis positive women whose first prenatal visits were very close to the delivery due dates; hence, their intervention time periods were shorter than for normal treatment courses. Among those who refused treatment, we found five cases of congenital syphilis. Only four cases could be attributed to intervention failure.

\section{Intervention effectiveness}

The average incidence rate of mother-to-child transmission (number of congenital syphilis/number of pregnant women screened) was 22.0 cases per 100000 pregnant women (92/ $477656)$ over three years, which is much lower than the rate of 53.6 cases $(63 / 117510)$ per 100000 pregnant women in 2002. For the years 2003, 2004, and 2005, this transmission rate was 


\begin{tabular}{|c|c|c|c|c|}
\hline Factors & $\begin{array}{l}\text { No of women screened } \\
(\%)\end{array}$ & $\begin{array}{l}\text { No syphilis positive } \\
(\%)\end{array}$ & $\begin{array}{l}\text { Positive rate } \\
(\%)\end{array}$ & $\chi^{2}$ lp? \\
\hline \multicolumn{5}{|l|}{ Age } \\
\hline$<20$ & $13404(3.2)$ & $65(3.2)$ & 0.5 & \multirow{5}{*}{$\begin{array}{l}11.5 \\
(0.022)\end{array}$} \\
\hline $20-24$ & $157998(37.7)$ & $759(37.6)$ & 0.5 & \\
\hline $25-29$ & $169559(40.5)$ & 771 (38.2) & 0.5 & \\
\hline $30-34$ & $66349(15.8)$ & $372(18.4)$ & 0.6 & \\
\hline$\geqslant 35$ & $11560(2.8)$ & $52(2.6)$ & 0.5 & \\
\hline \multicolumn{5}{|l|}{ Educational background } \\
\hline Illiterate/primary school & 175632 (41.9) & 309 (15.3) & 0.2 & \multirow{4}{*}{$\begin{array}{l}2699.8 \\
(0.000)\end{array}$} \\
\hline Junior high school & 62286 (14.9) & $1077(53.4)$ & 1.7 & \\
\hline Senior high school & 75899 (18.1) & $505(25.0)$ & 0.7 & \\
\hline Higher education & $105054(25.1)$ & $128(6.3)$ & 0.1 & \\
\hline \multicolumn{5}{|l|}{ Occupation } \\
\hline Worker & $53741(12.8)$ & $273(13.5)$ & 0.5 & \multirow{7}{*}{$\begin{array}{l}508.7 \\
(0.000)\end{array}$} \\
\hline Farmer & 15666 (3.7) & $82(4.1)$ & 0.5 & \\
\hline Civil servant & $8252(2.0)$ & $6(0.3)$ & 0.1 & \\
\hline Professional & $63752(15.2)$ & $52(2.6)$ & 0.1 & \\
\hline Commercial/service personnel & 28609 (6.8) & $228(11.3)$ & 0.8 & \\
\hline Unemployed & $148992(35.6)$ & $1052(52.1)$ & 0.7 & \\
\hline Others & 99859 (23.8) & $326(16.1)$ & 0.3 & \\
\hline \multicolumn{5}{|l|}{ District } \\
\hline Luohu & 32318 (7.7) & $189(9.4)$ & 0.6 & \multirow{6}{*}{$\begin{array}{l}35.6 \\
(0.000)\end{array}$} \\
\hline Futian & 69130 (16.5) & 297 (14.7) & 0.4 & \\
\hline Nanshan & $59791(14.3)$ & $235(11.6)$ & 0.4 & \\
\hline Baoan & $182487(43.6)$ & $911(45.1)$ & 0.5 & \\
\hline Longgang & 68686 (16.4) & 372 (18.4) & 0.5 & \\
\hline Yantian & 6459 (1.5) & $15(0.7)$ & 0.2 & \\
\hline \multicolumn{5}{|l|}{ Residency status (Hukou) } \\
\hline Local & 53532 (12.8) & $212(10.5)$ & 0.4 & \multirow{3}{*}{$\begin{array}{l}68.5 \\
(0.000)\end{array}$} \\
\hline Temporary & $179360(42.8)$ & $1048(51.9)$ & 0.6 & \\
\hline Floating & $185979(44.4)$ & 75937.6() & 0.4 & \\
\hline \multicolumn{5}{|l|}{ Gestational weeks at first diagnosis } \\
\hline$<5$ & $7540(1.8)$ & $36(1.8)$ & 0.5 & \multirow{11}{*}{$\begin{array}{l}151.6 \\
(0.000)\end{array}$} \\
\hline $5-8$ & $50767(12.1)$ & $228(11.3)$ & 0.5 & \\
\hline $9-12$ & $72213(17.2)$ & 227 (11.2) & 0.3 & \\
\hline $13-16$ & 54202 (12.9) & $237(11.7)$ & 0.4 & \\
\hline $17-20$ & 39290 (9.4) & 215 (10.7) & 0.6 & \\
\hline $21-24$ & $35730(8.5)$ & $142(7.0)$ & 0.4 & \\
\hline $25-28$ & $26891(6.4)$ & 188 (9.3) & 0.6 & \\
\hline $29-32$ & $25844(6.2)$ & 205 (10.2) & 0.8 & \\
\hline $33-36$ & $28316(6.8)$ & $164(8.1)$ & 0.6 & \\
\hline $37-40$ & $70454(16.8)$ & $321(15.9)$ & 0.5 & \\
\hline$\geqslant 41$ & 7204 (1.7) & $55(2.7)$ & 0.8 & \\
\hline Total (for each section) & 418871 (100.0) & $2019(100.0)$ & 0.48 & ? \\
\hline
\end{tabular}

20.3 (24/118 235), 15.5 (22/141 619), and 28.9 (46/159 017) cases per 100000 pregnant women, respectively.

The average incidence rate of congenital syphilis in syphilis positive pregnant women was $4.6 \%$ (92/2019) over the three years. For individual years, the rates were $4.3 \%$ (24/555), 3.5\% $(22 / 637)$, and $5.6 \%(46 / 827)$ in 2003, 2004, and 2005, respectively. Despite intervention, a total of 92 cases of congenital syphilis were reported. However, 76 cases were born to women who missed out on the screening programme, and were therefore either diagnosed with congenital syphilis at the time of delivery, or were delivered at home and diagnosed later. Another five infants were born to women who refused treatment, and seven were born to mothers who had late diagnosis or treatment. The success rate for mother-to-child transmission intervention (number of successful interventions/ number of syphilis positive women who received intervention) was $99.1 \%$ (1752/1768). If those who were diagnosed and treated late in pregnancy are excluded, the success rate would be even higher.

\section{DISCUSSION}

WHO estimated that every year there are at least half a million infants born with congenital syphilis, and half a million stillbirths and miscarriages resulting from maternal syphilis. ${ }^{11}{ }^{12}$

China's national policy for syphilis control, as well as the local government's financial and political support, contributed

Table 3 Pregnancy outcomes of women infected with syphilis

\begin{tabular}{rrrrrr}
\hline Year & $\begin{array}{l}\text { Abnormal } \\
\text { pregnancy } \\
(\%)\end{array}$ & $\begin{array}{l}\text { Termination } \\
\text { of pregnancy } \\
(\%)\end{array}$ & $\begin{array}{l}\text { Continued } \\
\text { pregnancy } \\
(\%)\end{array}$ & \multicolumn{1}{l}{$\begin{array}{l}\text { Follow-up loss } \\
(\%)\end{array}$} & \multicolumn{1}{l}{$\begin{array}{l}\text { Total } \\
(\%)\end{array}$} \\
\hline 2003 & $82(14.8)$ & $99(17.8)$ & $330(59.5)$ & $44(7.9)$ & $555(100.0)$ \\
2004 & $92(14.4)$ & $97(15.2)$ & $445(69.9)$ & $3(0.5)$ & $637(1000)$ \\
2005 & $122(14.8)$ & $78(9.4)$ & $627(75.8)$ & $0(0.0)$ & $827(100.0)$ \\
Total & $296(14.7)$ & $274(13.6)$ & $1402(69.4)$ & $47(2.3)$ & $2019(100.0)$ \\
\hline
\end{tabular}


Table 4 Factors associated with congenital syphilis

\begin{tabular}{lllllll}
\hline $\begin{array}{l}\text { Hospital } \\
\text { delivery* } \\
(\%)\end{array}$ & $\begin{array}{l}\text { Out-of-hospital } \\
\text { delivery* } \\
(\%)\end{array}$ & $\begin{array}{l}\text { Late screening } \\
(\%)\end{array}$ & $\begin{array}{l}\text { Refused } \\
\text { treatment } \\
(\%)\end{array}$ & $\begin{array}{l}\text { Treatment failure } \\
(\%)\end{array}$ & $\begin{array}{l}\text { Total } \\
(\%)\end{array}$ \\
\hline 2003 & $16(66.7)$ & $4(16.7)$ & $2(8.3)$ & $1(4.2)$ & $1(4.2)$ & $24(100.0)$ \\
2004 & $11(50.0)$ & $6(27.3)$ & $2(9.1)$ & $2(9.1)$ & $1(4.5)$ & $22(100.0)$ \\
2005 & $31(67.4)$ & $8(17.4)$ & $3(6.5)$ & $2(4.3)$ & $2(4.3)$ & $46(100.0)$ \\
Total $58(63.0)$ & $18(19.6)$ & $7(7.6)$ & $5(5.4)$ & $4(4.3)$ & $92(100.0)$ \\
\hline *Delivery without antenatal intervention.
\end{tabular}

to the successful implementation of the intervention programme in Shenzhen. The success also required technical support and a good antenatal service in the city, all of which were present.

The three-year implementation of this project was extremely successful in the prevention of mother-to-child syphilis transmission. Screening coverage reached $94.0 \%$, and the success rate of intervention was 99.1\%. Between 2003 and 2005, the average incidence rate of congenital syphilis was 22.0 cases per 100000 pregnant women screened (about 31 cases annually), less than half of the incidence rate in 2002 (63 cases in total, or 48.5 cases per 100000 pregnant women) when the project first started. Our project confirmed that screening is effective in enabling pregnant women to receive treatment, and efficient in the control and prevention of congenital syphilis. This has a large impact on syphilis control practice, as well as reducing the medical, social, and economic consequences that result from untreated syphilis in mothers to be.

In our study, the pregnant women who had syphilis were most likely to be young, migratory, with low education backgrounds, and who worked in the production or service industries within the commercial sector (excluding sex workers). Most of them lived in the Longgang or Baoan districts outside the Shenzhen Economic Zone (SEZ), or in the Luohu district inside the SEZ. As the commercial centre, Luohu has the largest number of commercial activities. Baoan and Longgang are industrial centres harbouring factories where the young, floating population and the commercial personnel congregated. These people generally had little education, and mainly worked in either service or production industries. They usually had very poor knowledge of the prevention of sexually transmitted diseases (STDs), and had little contact with the healthcare system, making them at high risk of STD infection. ${ }^{13}{ }^{14}$ These vulnerable groups need to be targeted.

The failure to follow-up was a major problem. In Shenzhen, the majority of the migratory population changed their jobs, residences, and telephone numbers frequently, causing extreme difficulties with any attempts at follow-up. Moreover, the highest loss rate occurred in pregnant women who chose to return to their home towns. Better contact methods and more

\section{Key messages}

- A programme to screen pregnant women for syphilis in Shenzhen, China, succeeded in detecting cases and preventing the mother-to-child transmission of syphilis.

- Financial and political support from the central and local government was vital for the programme's successful implementation

- Pregnant women who were poorly educated, unemployed, or engaged in commercial services were at higher risk of syphilis infection detailed information are necessary. The provision of a point-ofcontact syphilis test with immediate treatment might solve many of these issues.

Congenital syphilis was less likely if the pregnant women with syphilis were treated before the beginning of the third trimester (28 weeks). However, some pregnant women came to hospital for prenatal care in the last trimester of their pregnancies, or at the time of delivery, when congenital syphilis had, unfortunately, already occurred. Further study is required to analyse the reasons for the refusal of treatment or for late antenatal care, and thus work out potential ways to encourage early antenatal care and testing.

We are assessing the screening tests, treatments, and partner notification strategies further in collaboration with domestic and international specialists, to improve effectiveness of the programme. Hopefully, the success of this project will lead to the scaling up of prenatal syphilis screening throughout China, and will contribute to some of WHO's millennium goals in improving maternal health and reducing child mortality.

Contributors: JQC and HZ designed the programme, arranged quality control, and wrote the paper; FCH was responsible for the clinical management of the patients; PP analysed laboratory data; DZ and YJZ organised and implemented the programme; YMC collected and analysed the data.

\section{Authors' affiliations}

J Q Cheng, Shenzhen Center for Disease Control and Prevention, Shenzhen 518020, China

J Q Cheng, H Zhou, F C Hong, P Pan, Y M Cai, Shenzhen Center for Chronic Diseases Prevention and Control, Shenzhen 518020, China

D Zhang, Y J Zhang, Shenzhen Health Bureau, Shenzhen 518020, China

\section{REFERENCES}

1 Ray JG. Lues-lues: maternal and fetal considerations of syphilis. Obstet Gynecol Surv 1995; 50:845-50.

2 Finelli L, Berman SM, Koumans EH, et al. Congenital syphilis. Bull World Health Organ 1998;76:126-7.

3 Zhong XC, Hong FC, Luo B, et al. Analysis on the epidemiology of syphilis from 1984 to 2001 in Shenzhen. Mod Prev Med 2003;30:34-5.

4 Hong FC, Zhou H, Luo B, et al. Status of pregnancy complicated syphilis in Shenzhen. Mod Prev Med 2004;31:623-4.

5 Cheng JQ, Zhang D, Zhou $\mathrm{H}$, et al. Strategy on syphilis prevention of mother-tochild transmission in Shenzhen. Chin J Public Health 2004;20:1190-1.

6 Terris-Prestholt F, Waston D, Mugeye K, et al. Is antenatal syphilis screening still cost effective in sub-Saharan Africa? Sex Transm Infect 2003;79:375-81.

7 Stray-Pdeersen B. Economic evaluation of maternal screening to prevent congenital syphilis. Sex Transm Dis 1983;10:167-72.

8 Ye ZS, Zhang MY. Contemporary experimental diagnostic technology of sexually transmitted diseases. Guangzhou: Guangdong Science and Technology Press, 1999.

9 The MOP Counselling Committee on Sexually Transmitted Diseases. Guidelines for the diagnosis and control of congenital syphilis, Beijing, 2000.

10 Centers for Disease Control and Prevention. Sexually transmitted diseases treatment guidelines 2002. MMWR Recomm Rep 2002;51:1-78.

11 World Health Organization. Eliminating congenital syphilis. http:// www.who.int/reproductive-health/stis/syphilis.html.

12 Aiken CG. The causes of perinatal mortality in Bulawayo, Zimbabwe. Cent Afr J Med 1992;38:263-81.

13 Blondel B, Marshall B. Poor antenatal care in 20 French districts: risk factors and pregnancy outcome. J Epidemiol Community Health 1998;52:501-6.

14 Mullick S, Watson-Jones D, Beksinska M, et al. Sexually transmitted infections in pregnancy: prevalence, impact on pregnancy outcomes, and approach to treatment in developing countries. Sex Transm Infect 2005;81:294-302. 